\section{Increased birth weight in northerly islands: is fish consumption a red herring?}

\author{
Valerie Harper, Ronella MacInnes, \\ Doris Campbell, Marion Hall
}

Department of Obstetrics and Gynaecology, University of Aberdeen, Áberdeen AB9 2ZD

Valerie Hárper, MRCOG, research fellow

Doris Campbell, FRCOG, senior lecturer

Marion Hall, FRCOG,

clinical senior lecturer

Health Centre, Kirkwall, Orkney

Ronella MacInnes, DRCOG, general practitioner

Correspondence to: Dr Harper.

BMf 1991:303:166 and $\mathrm{A}$ Walker, personal communication).

\section{Patients, methods, and results}

Babies born to residents of the Faeroe Islands have been reported to be heavier than babies born to other Scandinavians and international averages. ${ }^{1}$ No explanation for this finding was given, but it has since been suggested that the increase in birth weight may be due to the high dietary intake by the Faeroese of (n-3) polyunsaturated fatty acids from fish. ${ }^{2}$ To investigate this further we compared the birth weights of live singleton infants born to mothers resident in the Orkney Islands with the birth weights of similar infants born to mothers living in Aberdeen, on the Scottish mainland. Determinants of birth weight were compared in the two populations. The Orcadians eat $30 \%$ more fish than the Aberdonians ${ }^{3}$. A Anderson

Singleton live births to women resident in Orkney $(n=899)$ during 1980-4 were identified from the Scottish morbidity record 2, and information was extracted from the case notes by one observer (RM). Residents of Orkney who delivered in Aberdeen during this period $(n=116)$ were identified, and data were extracted from the Aberdeen maternity and neonatal databank. All singleton live births to women resident in Aberdeen City district in $1982(n=2997)$ were chosen as controls. The information obtained for each birth consisted of maternal parity, age, height, weight at 20 weeks' gestation, smoking habit, marital status, complications of pregnancy, birth weight and sex of the infant, and gestational age at delivery. Data were analysed with the statistical package for the social sciences X. The $z$ test was used to compare the mean maternal age, height, weight, number of cigarettes smoked by smokers, birth weight of the infants, and gestational age at delivery. The number of smokers, distribution of parity, marital status, and birth weight centiles were compared with the $\chi^{2}$ test. Birthweight standards used were derived from Aberdeen City district deliveries.

During 1980-4 the mean birth weight of the babies born to women resident in Orkney was 3521 (SD 504) g and that of the babies born to women resident in Aberdeen was 3287 (544) g. The proportion of male

Steps in multiple regression analysis of birth weight

\begin{tabular}{llrrrrr}
\hline & Variable & $\mathbf{R}^{2}$ & $\begin{array}{r}\text { Regression } \\
\text { coefficient }\end{array}$ & $\begin{array}{r}\text { Standard } \\
\text { error }\end{array}$ & $F$ & $F$ change \\
\hline 1 & Gestation & $0 \cdot 371$ & $165 \cdot 1$ & $4 \cdot 0$ & 1556 & \\
2 & Maternal weight at 20 wecks & $0 \cdot 418$ & $7 \cdot 9$ & $0 \cdot 8$ & 946 & $212 \cdot 2$ \\
3 & Mother a smoker or not & $0 \cdot 449$ & $-186 \cdot 2$ & $17 \cdot 4$ & 717 & $151 \cdot 2$ \\
4 & Sex of baby & $0 \cdot 465$ & $-141 \cdot 7$ & $16 \cdot 1$ & 573 & $77 \cdot 4$ \\
5 & Parity & $0 \cdot 479$ & $72 \cdot 7$ & $8 \cdot 6$ & 484 & $71 \cdot 1$ \\
6 & Maternal height & $0 \cdot 487$ & $8 \cdot 9$ & $1 \cdot 4$ & 417 & $41 \cdot 8$ \\
7 & Residents of Orkney & $0 \cdot 489$ & $62 \cdot 4$ & $18 \cdot 6$ & 360 & $11 \cdot 2$
\end{tabular}

All $F$ values and $F$ changes were significant.

infants delivered to the two groups was the same. Gestational age was prolonged in the Orkney women by 0.36 weeks. Altogether $186(18.3 \%)$ babies in Orkney were over the 90 th centile for birth weight corrected for gestational age at delivery and parity compared with $300(10.0 \%)$ babies in Aberdeen; 49 $(4 \cdot 8 \%)$ babies in Orkney were below the 10th centile compared with $365(12 \cdot 2 \%)$ babies in Aberdeen. The women in Orkney were taller and heavier than the women in Aberdeen: mean heights were $161(6 \cdot 1) \mathrm{cm}$ and $160(6 \cdot 1) \mathrm{cm}$ respectively, and mean weights at 20 weeks' gestation were $66 \cdot 34(10 \cdot 3) \mathrm{kg}$ and $62 \cdot 2(10 \cdot 2)$ $\mathrm{kg}$, respectively. The women in Orkney were slightly older (mean age $27 \cdot 0(5 \cdot 1)$ years) than the women in Aberdeen (mean age 26.2 (4.9) years). Altogether 332 $(36.9 \%)$ of the women in Orkney were primigravidas compared with $54(46 \cdot 2 \%)$ of the women in Aberdeen. A smaller proportion of women in Orkney smoked (148 (16.5\%) compared with $48(41.4 \%)$ of women in Aberdeen), and the mean number of cigarettes smoked per day by the smokers in Orkney was lower $(9 \cdot 3(7 \cdot 0)$ compared with $14 \cdot 9(7 \cdot 1)$ ).

The differences between the above variables were significant at the $1 \%$ level. The effect of each variable on birth weight was determined by a multiple regression analysis in a stepwise manner (table). The variables maternal age and marital status were also tested but did not affect birth weight significantly.

\section{Comment}

Birth weights of babies born to residents of Orkney are significantly higher than those of babies born to residents of Aberdeen City district even after correction for gestational age at delivery and parity. The small difference in gestational age may be due to the higher proportion of mothers in Aberdeen who smoke as smoking shortens the period of gestation by $0 \cdot 2-0 \cdot 4$ weeks. ${ }^{4}$ Most of the difference in the weight of babies of residents of Orkney and Aberdeen can be explained by the differences in maternal weight, height, and smoking habit. A small but significant proportion of the variation in birth weight was explained by the mother being a resident of Orkney. This may be due to genetic or environmental factors such as diet. Any hypothesis concerning dietary causes of increased birth weight must take into account other known determinants of birth weight.

VH was funded by a fellowship in computing experience from the Scottish Home and Health Department. We thank all the general practitioners in Orkney and the consultants in Aberdeen Maternity Hospital for access to the patients records, and Dr Gordon Patterson, consultant in public health medicine, Grampian Health Board, for information on women delivering in Orkney.

1 Olsen SF, Joensen HD. High liveborn birthweights in the Faroes: a compariso between birthweights in the Faroes and in Denmark. I Epidemiol Community Health 1985;39:27-32.

2 Olsen SF, Hanson HS, Sorensen TIA, Sensen B, Secher NJ, Sommer S, et al. Intake of marine fat, rich in (n-3) polyunsaturated fatty acids, may increase birthweight by prolonging gestation. Lancet 1986;ii:367-9.

3 Barber SA, Ball NG, Cameron AM. A dietary survey of an isolated populatio in the UK. The islanders of Orkney. Human Nutr Appl Nutr 1986;40A $462-9$.

4 Pirani DH, Pirani BBK. Smoking during pregnancy. Obstet Gynecol Suro 1978;33:1-13.

(Accepted 5 March 1991$)$ 